angiography one can predict not only the localization of lesions, but also their pathology. This is often true, but by no means aiways so. One has seen gliomas giving appearances indistinguishable from meningiomas, and other malignant gliomas failing to reveal pathological vessels at any stage from early arteriography to late plebography. Attractive though it may be to hope that the radiograph will substitute for the microscope in the pathological diagnosis of many brain tumours, that stage has been reached in only a minority of cases. None the less no one interested in neurology can afford to disregard the very useful information provided by angiography, which has become an essential diagnostic tool, in large measure thanks to the author of the book. It is to be strongly recommended.

J.W.D.B.

\section{SURGERY OF CATARACT}

By Daniel B. KIRby, A.M., M.D., LL.D. Pp. xx + 695, with 339 illustrations, 21 in colour. London and New York: J. B. Lippincott. 1950. fi2.

It may seem strange to an outsider that a book of nearly 700 pages can be written about one operation which frequently takes less than 15 minutes to perform, but it must be remembered that the cataract operation occupies a very special place in the life and heart of the ophthalmic surgeon, often being the yardstick by which his competence is measured.

Albeit, this is a monumental work, touching on a wide variety of subjects concerned, some of them rather remotely, with cataract surgery. History, anatomy, physiology, the training of a cataract surgeon and his approach not only to his patient but even to his Maker are not neglected. There is a good deal of rather fulsome repetition in this part of the book, which might have been more severely edited.

The main emphasis is naturally on the intracapsular operation, to which Dr. Kirby has made important contributions, and this, the largest section of the book, is very well done and fascinating to read. Dr. Kirby reviews the work of other surgeons, usually in their own words, by means of long extracts from their writings, and then explains his own conclusions not in the form of a rigid 'method,' but in an elastic 'system' by which he can adapt himself to the varying conditions found both before and during the operation. He believes that the cataract surgeon should have at his command a large variety of manoeuvres and should be able to choose, use and alter them at will. $\mathrm{He}$ is thus no bigot and has obviously been receptive of new ideas during 30 years of operating experience. He frequently puts forward his own innovations, particularly his cylindrical-handled instruments, not suggesting that all surgeons should adopt them but that they should try them if their own technique is not yielding the results that they expect.

The book is admirably produced and the coloured illustrations are excellent. Inevitably no one of his readers will agree with all that Dr. Kirby says, but this, so far from being a drawback, will stimulate them to re-examine their own technique and see what can be learnt from this very lively mind. Many may without loss take father's advice for reading Scott's novels and skip the first few chapters.

\section{WHEELER AND JACK'S HANDBOOK OF MEDICINE}

Revised by Robert CoOpe, M.D., B.Sc., F.R.C.P. I Ith Edition. Pp. xvi +648 , with 62 illustrations. Edinburgh: E. \& S. Livingstone. $195^{\circ}$. 20 .

The student who holds that it is inadvisable to see patients for a period of three months preceding the final examination, on the grounds that they tend to confuse the clear picture of disease required for this hurdle, would do well to digest the fureword to this handbook. 'Our art is not to be learned save by its exercise and use,' and this book, of a size to be admitted into a capacious pocket, is an ideal practical companion for the period of clinical clerking.

\section{THE BRITISH ENCYCLOPAEDIA OF MEDICAL PRACTICE (Vol. 2)}

Edited by The RT. HoN. LORD HORDER, G.C.V.O., M.D., F.R.C.P. and Edition. Pp. xiii + 755, with 115 illustrations. London: Butterworth and Co. 1950. f3.

The high standard of the first volume has been maintained in the present work, which has been expanded by the introduction of two new chapters on atomic energy and blast injuries. These new sections, excellently written by Dr. J. F. Loutit and Sir Cecil Wakeley respectively, together with the greatly expanded chapter on aviation medicine by Sir Harold Whittingham, are not only an index of the perilous times in which we live, but also a sharp reminder of the increasingly important part that doctors would be expected to play in any future war. All three chapters, therefore, will repay close study.

New contributors will be welcomed amongst the authors of the first edition. In this regard, Dr. W. Tegner's excellent accounts of ankylosing spondylitis and backache should be mentioned. The section on ascites has been rewritten with advantage by Dr. G. E. Beaumont, who recognizes the fact that some doctors may have had a classical education, and, perhaps, have not forgotten all their Greek. Mr. V. Zachary Cope, our doyen amongst 